\title{
An intercomparison of radar-based liquid cloud microphysics retrievals and implications for model evaluation studies
}

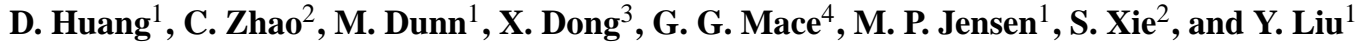 \\ ${ }^{1}$ Brookhaven National Laboratory, Upton, NY 11973, USA \\ ${ }^{2}$ Lawrence Livermore National Laboratory, Livermore, CA 94550, USA \\ ${ }^{3}$ University of North Dakota, Grand Forks, ND 58202, USA \\ ${ }^{4}$ University of Utah, Salt Lake City, UT 84112, USA
}

Correspondence to: D. Huang (dhuang@bnl.gov)

Received: 8 November 2011 - Published in Atmos. Meas. Tech. Discuss.: 5 December 2011

Revised: 18 May 2012 - Accepted: 29 May 2012 - Published: 25 June 2012

\begin{abstract}
This paper presents a statistical comparison of three cloud retrieval products of the Atmospheric Radiation Measurement (ARM) program at the Southern Great Plains (SGP) site from 1998 to 2006: MICROBASE, University of Utah (UU), and University of North Dakota (UND) products. The probability density functions of the various cloud liquid water content (LWC) retrievals appear to be consistent with each other. While the mean MICROBASE and UU cloud LWC retrievals agree well in the middle of cloud, the discrepancy increases to about $0.03 \mathrm{gm}^{-3}$ at cloud top and cloud base. Alarmingly large differences are found in the droplet effective radius $\left(r_{\mathrm{e}}\right)$ retrievals. The mean MICROBASE $r_{\mathrm{e}}$ is more than $6 \mu \mathrm{m}$ lower than the UU $r_{\mathrm{e}}$, whereas the discrepancy is reduced to within $1 \mu \mathrm{m}$ if columns containing raining and/or mixed-phase layers are excluded from the comparison. A suite of stratified comparisons and retrieval experiments reveal that the LWC difference stems primarily from rain contamination, partitioning of total liquid later path (LWP) into warm and supercooled liquid, and the input cloud mask and LWP. The large discrepancy among the $r_{\mathrm{e}}$ retrievals is mainly due to rain contamination and the presence of mixed-phase layers. Since rain or ice particles are likely to dominate radar backscattering over cloud droplets, the large discrepancy found in this paper can be thought of as a physical limitation of single-frequency radar approaches. It is therefore suggested that data users should use the retrievals with caution when rain and/or mixed-phase layers are present in the column.
\end{abstract}

\section{Introduction}

It has been long recognized that inadequate representation of clouds is largely responsible for the high degree of uncertainty associated with the magnitude of model-predicted climate change induced by changes of carbon dioxide, other trace gases, and aerosols (Stephens, 2005). The outstanding issues of cloud parameterizations are not only a result of the complexity of the cloud problem itself but also the difficulty in observing and measuring the cloud properties and cloud life cycles used in model evaluation (Randall et al., 2003). The spatial distribution of cloud microphysical properties such as cloud liquid water content (LWC) and droplet effective radius $\left(r_{\mathrm{e}}\right)$, in particular, affects the cloud's interaction with solar and infrared radiation ultimately contributing to the energy budget at the surface, at the top-of-atmosphere (TOA), and in the atmospheric column. Observations of the cloud microphysical structure and life cycle are also essential for high-resolution modeling studies, which are essential for improving our understanding of the processes acting to form and maintain cloud systems.

The Atmospheric Radiation Measurement (ARM) Climate Research Facility of the US Department of Energy provides long-term continuous cloud and radiation datasets from surface-based sites in several different climate regimes around the globe (Stokes and Schwartz, 1994; Ackerman and Stokes, 2003). The site at the Southern Great Plains (SGP) of the USA has been collecting observations of clouds, radiation and atmospheric state since the spring of 1992. Various retrieval algorithms have been developed to obtain the cloud 
properties using ARM ground-based millimeter wavelength cloud radars, lidars, passive microwave radiometers, and a variety of shortwave and longwave radiation sensors (Dong et al., 1998; Mace et al., 2006; Dunn et al., 2011).

Given the importance and complexity of cloud representation in climate predictions, an increasing number of studies have been devoted to evaluating model performance in simulating cloud microphysical properties using observed cloud properties (Xie et al., 2005; Klein et al., 2009). However, without comparison of different retrievals, previous studies often selected a single retrieval product as observational truth. For the various cloud microphysical retrieval products to be useful for various applications - including model evaluation, parameterization development, and understanding cloud processes - the uncertainty in the retrievals has to be quantified. The estimated uncertainties by data producers in retrieved LWC, liquid droplet $r_{\mathrm{e}}$, IWC, and ice $r_{\mathrm{e}}$ range from $10-100 \%, 10-60 \%, 10-100 \%$, and 10-50\%, respectively (Zhao et al., 2012). However, these estimations are usually based on a limited number of cases over limited periods. As Zhao et al. (2012) indicated, the differences among various cloud products could be much larger than these estimated uncertainties. Considering the large variety of different cloud observation/retrieval techniques, the community has become increasingly aware of the importance of quantifying the uncertainty of different cloud retrievals.

Given the complexity of cloud processes themselves and the huge scale mismatch between in-situ and remotely sensed observations, systematic studies that employ different uncertainty quantification techniques are necessary to obtain a comprehensive image of the accuracy of cloud retrievals (Zhao et al., 2012). One approach to characterize the cloud retrieval uncertainty is to use Observation System Simulation Experiments (OSSEs) to track how the uncertainty in the input measurements and in the underlying forward model propagates to the final retrievals. Observed or simulated cloud properties can be used to generate remote sensing measurements and then the retrieval is applied, allowing the quantification of the error directly by comparison with original observations or simulations (Löhnert et al., 2007). However, most existing algorithms are empirical to some extent and the uncertainties associated with the underlying assumptions are difficult to quantify. A second approach involves comparing the retrievals with direct cloud measurements such as those from in-situ cloud probes (Sassen et al., 1999; Mace and Sassen, 2000). This approach is hampered by a scarcity of coincident surface-based and aircraft measurements and the dramatic mismatch between the radar and in-situ probe sampling volumes. A third approach is to use retrieved cloud properties in radiative transfer calculations and evaluate the shortwave and longwave radiation closure (Mace and Benson, 2008). The discrepancy between calculated and measured radiation can serve as an indicator of the quality of the cloud retrievals (McFarlane and Evans, 2004; Ebell et al., 2010). The radiation closure approach cannot provide a conclusive measure of the quality of cloud retrievals because different combinations of cloud properties can result in similar radiation closure results although using both surface and top-of-atmosphere closure approaches does mitigate this issue somewhat. A fourth approach is to compare different cloud retrieval products and quantify the spread between the products in light of physical constraints on what is known from in-situ data. This approach does not provide a quantification of the true uncertainty in the cloud retrievals but rather provides a quantification of the differences between various products. The quantitative information on the spread of existing retrievals is useful for model evaluation. This is the focus of this paper.

This paper compares the cloud LWC and $r_{\mathrm{e}}$ retrievals from several different approaches for liquid phase clouds. The retrievals for ice clouds are generally less accurate due to the complexity of radiation scattering and transport through highly inhomogeneous crystalline clouds (Comstock et al., 2007). We also attempt to pinpoint the primary causes of the large differences between different radar-based cloud retrievals and to understand the limitation of the singlefrequency radar approaches. The paper is organized as follows. Section 2 provides the theoretical basis of cloud microphysical retrievals using combined radar and microwave radiometer measurements. Section 3 provides a description of the retrieval algorithms used to produce the three cloud microphysical products. Section 4 presents the comparison results and Sect. 5 discusses possible reasons for the discrepancy between various cloud retrieval products. Section 6 discusses the implication of these comparison results for model evaluations. Section 7 summarizes the findings of this study.

\section{Background of warm cloud microphysics retrieval}

The potential of using millimeter wavelength radar to observe clouds has been recognized for a few decades (Hobbs et al., 1985; Lhermitte, 1987; Frisch et al., 1995, 1998; Kollias, et al., 2005; Matrosov, 2005). The theory of cloud detection by millimeter radar can be found in Doviak and Zrnic (1993) and Clothiaux et al. (1995) and is briefly introduced below.

The radar reflectivity factor $(Z)$ for non-raining clouds with a droplet size distribution $n(r)$ is given by:

$Z=64 \int_{0}^{\infty} n(r) r^{6} \mathrm{~d} r$

where $r$ is the droplet radius. Similarly, the cloud LWC can be written as:

$\mathrm{LWC}=\frac{4}{3} \pi \rho_{\mathrm{L}} \int_{0}^{\infty} n(r) r^{3} \mathrm{~d} r$,

where $\rho_{\mathrm{L}}$ is the density of liquid water.

Cloud droplet $r_{\mathrm{e}}$ can be expressed as the ratio of the third moment to the second moment of droplet size distribution:

$r_{\mathrm{e}}=\int_{0}^{\infty} n(r) r^{3} \mathrm{~d} r / \int_{0}^{\infty} n(r) r^{2} \mathrm{~d} r$. 
A functional form of the droplet size distribution is often assumed in retrievals and usually the choice of this functional form has only a minimum impact on radar retrieval algorithms (Frisch et al., 1995). Here we use the lognormal distribution as an example due to its wide use in radar retrieval algorithms,

$n(\ln r)=\frac{N}{\sigma \sqrt{2 \pi}} \exp \left[-\left(\ln r-\ln r_{0}\right)^{2} / 2 \sigma^{2}\right]$,

where $N, r_{0}$, and $\sigma$ are the total droplet number concentration, geometric mean droplet radius, and standard deviation of droplet size distribution, respectively. For the lognormal distribution, radar reflectivity can be related to cloud LWC and $r_{\mathrm{e}}$ using the following equations:

$Z=48 \mathrm{LWC}^{2} \exp \left(9 \sigma^{2}\right) /\left(\pi \rho_{\mathrm{L}} N\right)$

$Z=64 N r_{\mathrm{e}}^{6} \exp \left(3 \sigma^{2}\right)$.

According to Eq. (5), radar reflectivity can be written as a function of cloud LWC (or $r_{\mathrm{e}}$ ), total cloud droplet number concentration, and geometric standard deviation of the droplet size distribution. In order to obtain cloud LWC and $r_{\mathrm{e}}$ from radar reflectivity measurements, certain assumptions have to be made about the cloud droplet size distribution (number concentration and standard deviation). Radar-based algorithms usually employ empirical Z-LWC relationships that are derived from aircraft measurements or numerical model simulations (e.g., Liao and Sassen, 1994). Deviation from the underlying assumptions of the size distribution, especially the presence of large particles (e.g., precipitation), results in non-unique relationships between LWC and radar reflectivity (Liu et al., 2008). It should be emphasized that when large drops co-exist with cloud droplets, the radar reflectivity measurements will be dominated by the large drops and thus contain little information about cloud droplets. It is therefore expected that under such conditions, cloud microphysical retrievals based only on radar reflectivity are doomed to be challenging and uncertain.

Several algorithms have been developed that use not only cloud radar observations but also passive observations to retrieve microphysical properties of clouds. Among them are the algorithms of Frisch et al. $(1995,1998)$ and Löhnert et al. (2001) that use column-integrated cloud LWP together with millimeter cloud radar reflectivity to constrain cloud microphysical retrievals. There are also algorithms that use the solar transmission as additional independent information to constrain cloud microphysical retrievals (Dong et al., 1997, 1998; Mace and Sassen, 2000). The algorithms using LWP and/or solar transmission usually assume that cloud droplet size distributions can be described by a functional form (lognormal or gamma) that can be characterized using only three independent parameters (two if assuming a fixed spectral dispersion parameter). As a result, such algorithms have similar limitations as the early Z-LWC algorithms, e.g., they are also vulnerable to the presence of precipitation.

\section{Description of retrieval algorithms}

This section provides a brief description of the three different radar algorithms used to retrieve cloud microphysical properties: the ARM baseline cloud microphysical properties product (MICROBASE; Dunn et al., 2011), University of Utah (UU) cloud product (Mace et al., 2006), and University of North Dakota (UND) cloud product (Dong and Mace, 2003). The underlying assumptions of these algorithms are also discussed in this section.

\subsection{Instruments}

The measurements used by the three algorithms are mainly from the ARM millimeter cloud radar (MMCR), the twochannel microwave radiometer, and the Vaisala balloonborne radio sounding systems. The MMCR is a vertically pointing Doppler radar operating at a frequency of $35 \mathrm{GHz}$ with a $0.19^{\circ}$ beamwidth. It is sensitive enough to see not only rain drops but also smaller cloud droplets. The uncertainty in MMCR radar reflectivity measurements is about $1 \mathrm{dBZ}$ (Moran et al., 1998). The microwave radiometer operates at 23.8 and $31.4 \mathrm{GHz}$ frequencies with a 20 -s sampling interval (Liljegren et al., 2001). The beamwidth is $5.5^{\circ}$ at $23.8 \mathrm{GHz}$ and $4.6^{\circ}$ at $31.4 \mathrm{GHz}$, more than one order wider than the MMCR. Water vapor and liquid water signals can be separated by observing at these two frequencies. The retrieval accuracy of LWP under low and intermediate liquid water conditions is about $30 \mathrm{gm}^{-2}$ (Turner et al., 2007).

\subsection{ARM MICROBASE algorithm}

The MICROBASE value-added product provides a continuous baseline microphysical retrieval, including vertical profiles of the liquid/ice water content and liquid/ice cloud particle $r_{\mathrm{e}}$ for all cloud conditions with ten-second time and 45-m vertical resolution. The best estimate radar reflectivity from the Active Remote Sensing of CLouds(ARSCL) value-added product (VAP) (Clothiaux et al., 2000), the LWP from the ARM Microwave Retrieval (MWRRET) VAP (Turner et al., 2007), and the atmosphere thermodynamic profiles from the ARM Merged Sounding value-added product (Troyan, 2010) are used as ancillary data for the MICROBASE algorithm. The specific algorithm used to convert radar/radiometer observations into cloud microphysical properties were chosen through a series of shortwave/longwave radiative closure studies (Mlawer et al., 2008).

The first step of the MICROBASE algorithm is to identify the phase of cloud particles. The MICROBASE phase partition is based on a simple criterion of temperature. Cloud particles are assumed to be all ice if air temperature is colder than $-16^{\circ} \mathrm{C}$, all liquid if temperature is warmer than $0^{\circ} \mathrm{C}$, 
and of a mixed phase, i.e., contains both ice and supercooled liquid water, if the temperature falls between $0{ }^{\circ} \mathrm{C}$ and $-16^{\circ} \mathrm{C}$. When a mixed phase cloud is identified, the liquid fraction is calculated as a linear function of temperature as given by:

$f_{\mathrm{L}}=(T+16) / 16,-16^{\circ} \mathrm{C} \leq T \leq 0^{\circ} \mathrm{C}$.

Conventional algorithms based on empirical Z-LWC relationships require absolute calibration of the cloud radar, which can be hard to perform in many cases. Using the LWP from a passive microwave radiometer as an overall constraint can mitigate the impact of absolute radar calibration on the retrieved cloud LWC profiles. The cloud layer boundaries are determined from the ARSCL best estimate radar reflectivity. The LWP from the microwave radiometer is then distributed vertically within the cloud layer(s) where $T>-16^{\circ} \mathrm{C}$ according to the following formula:

$$
\mathrm{LWC}_{i}=\mathrm{LWP} \frac{Z_{i}^{0.5556}}{\sum_{j=1}^{M} Z_{j}^{0.5556} \Delta z},
$$

where $\Delta z$ is the length of each radar range gate. The summation is for all the gates (i.e., radar resolution volumes) with a measureable radar reflectivity with $j=1$ denoting the lowest gate and $j=M$ denoting the highest gate that includes liquid water. The exponent 0.5556 is based on the results of Liao and Sassen (1994).

The additional LWP constraint from a microwave radiometer alleviates the impacts of absolute radar calibration and helps situations such as radar drift. The use of microwave radiometer LWP, however, could introduce a bias in retrieved LWC profiles. Since the microwave radiometer provides an estimate of only total LWP regardless of the temperature of the liquid water, it is necessary to use a parameterization to determine the warm and supercooled portion of LWP. The partitioning of total LWP into warm and supercooled liquid water could potentially introduce a bias in both warm and supercooled liquid water retrievals. In the MICROBASE algorithm, the radar reflectivity factor $Z_{\text {liq }}$ due to liquid water particles is used in place of $Z$ for mixed-phase cloud layers:

$Z_{\text {liq }}=f_{\mathrm{L}} Z$.

The MICROBASE algorithm assumes that cloud droplet size distribution follows a lognormal distribution. Cloud droplet $r_{\mathrm{e}}$ is calculated using the following equation:

$$
\begin{aligned}
r_{\mathrm{e}} & =\exp \left(2.5 \sigma^{2}\right)\left[\frac{3 \mathrm{LWC}}{4 \pi N \rho_{\mathrm{L}} \exp \left(4.5 \sigma^{2}\right)}\right]^{1 / 3} \\
& =0.0062 \exp \left(\sigma^{2}\right)\left[\frac{\mathrm{LWP}}{N \sum_{j=1}^{M} Z_{i}^{0.5556} \Delta z}\right]^{1 / 3} \\
& \exp [0.426 \log 10(Z)] .
\end{aligned}
$$

The droplet number concentration $N$ is assumed to be equal to $200 \mathrm{~cm}^{-1}$ and the geometric standard deviation of the droplet size distribution is assumed to be 0.35 for all the clouds at the SGP site because radar reflectivity measurements alone do not provide enough information to define them.

Several assumptions in the MICROBASE algorithm could potentially introduce large uncertainties in the resultant cloud microphysical retrievals. First, the linear relationship between cloud LWC and $Z^{0.5556}$ (Eq. 7) is questionable when large rain/ice particles coexist with cloud droplets since large particles will dominate radar backscattering while contributing little to total water mass. Second, the calculation of radar reflectivity due to liquid water using Eq. (8) for mixed-phase clouds lacks of a solid physical basis. Although in-situ observations generally show that the probability of supercooled liquid existence decreases with temperature, the linear partitioning of radar reflectivity in Eq. (8) is unrealistic given the large difference between ice and liquid particle sizes (Cober et al., 1995). Third, the assumption of fixed cloud droplet number concentration and spectral dispersion could also introduce large uncertainties to $r_{\mathrm{e}}$ retrievals.

\subsection{University of Utah algorithm}

The UU product has 5-min temporal resolution and 90-m vertical resolution. The UU algorithm also uses temperature as the main criterion for cloud phase classification. Cloud particles are assumed to be all liquid if the temperature is above the freezing point. When the temperature at radar echo top is colder than $-35^{\circ} \mathrm{C}$ and the maximum reflectivity occurs at temperature colder than $-20^{\circ} \mathrm{C}$, the cloud is considered to be pure ice cirrus. Otherwise, the cloud is classified as mixed phase (Mace et al., 2006).

Also similar to the MICROBASE, the UU cloud retrieval is constrained by the LWP obtained by a microwave radiometer using a statistical retrieval method (Liljegren et al., 2001). The cloud base height is determined by a Vaisala ceilometer and the cloud top is given by the last significant radar echo. The ceilometer operates at a $0.91 \mu \mathrm{m}$ wavelength with a maximum range of $7.5 \mathrm{~km}$. The UU cloud mask defined in this way can be different from the MICROBASE cloud mask due to its explicit use of ceilometer measurements.

With the column LWP and cloud boundaries, the next important step is to distinguish between the portion of the LWP from warm (i.e., temperature greater than freezing) cloud volumes and that from supercooled cloud volumes. This process is done with a parameterization used in the Community Climate System Model Version 3 where cloud LWC is assumed to decrease exponentially with height or temperature (Kiehl et al., 1998; Mace et al., 2006). The parameterization of Kiehl et al. (1998) is first used to determine the fraction of warm and supercooled liquid water contents. The MWR-derived LWP is then separated into warm and supercooled components, and the supercooled liquid water path 
is distributed vertically in the supercooled portion of cloud layers using the same parameterization (i.e., decrease exponentially with height) as a weighting function. It is assumed that the radar reflectivity in the supercooled portion contains information only from ice particles. The warm fraction of the LWP is distributed vertically using the Frisch et al. (1998) parameterization where the normalized square root of the radar reflectivity is used as a vertical weighting function:

$$
\mathrm{LWC}_{i}=\mathrm{LWP}_{\mathrm{warm}} \frac{Z_{i}^{0.5}}{\sum_{j=1}^{M} Z_{j}^{0.5} \Delta z} .
$$

Similar to Eq. (7), the summation is for all the cloudy gates with $j=1$ denoting the gate at cloud base and $j=M$ denoting the highest gate of measureable radar reflectivity that contains liquid water. It is noteworthy that both the MICROBASE and UU algorithms distribute LWC using the radar reflectivity factor as a weighting function; they differ only slightly in the choice of the exponent $(0.5556$ for the MICROBASE algorithm and 0.5 for the UU algorithm).

In the UU algorithm, the cloud droplet $r_{\mathrm{e}}$ is obtained using the following empirical formula derived from the work of Dong and Mace (2003):

$r_{\mathrm{e}}=19.5 \exp [0.384 \log 10(Z)]$.

The leading term in Eq. (11), i.e., 19.5 microns, was arrived at by varying the constants reported in Dong and Mace (2003) so that the resulting $r_{\mathrm{e}}$ produced a minimum bias between measured and calculated solar fluxes at the surface. This empirical relationship is based on a statistical regression of aircraft Forward Scattering Spectrometer Probe measurements collected during an intensive observational period (IOP) at the ARM SGP site in March 2001 (Dong and Mace, 2003). The formula is assumed valid only for $r_{\mathrm{e}}<10 \mu \mathrm{m} ; r_{\mathrm{e}}$ retrievals greater than $10 \mu \mathrm{m}$ are considered to be unreliable in view of possible contamination by precipitation particles. For supercooled liquid, $r_{\mathrm{e}}$ is assumed to be $15 \mu \mathrm{m}$. Several radiative closure studies have shown that the UU cloud retrievals are able to reproduce observed radiation fluxes at both the TOA and surface (Mace et al., 2006; Mace and Benson, 2008).

Similar to the MICROBASE algorithm, the assumption of a linear relationship between cloud LWC and $Z^{0.5}$ (Eq. 10) is vulnerable to the presence of large particles. The parameterization used to calculate supercooled LWC in mixed phase regions depends only on temperature and the estimated supercooled fraction of the MWR-derived LWP. Thus, the supercooled cloud retrievals should be considered as placeholders that can be improved in the future when better observational constraints are included. Lastly, the applicability of Eq. (11) to a variety of cloud types and conditions remains to be evaluated.

\subsection{University of North Dakota algorithm}

The UND product has the same temporal and vertical resolution as the UU product. The UND algorithm is designed to produce microphysical properties for only lowlevel stratus clouds. The low-level stratus clouds are defined mainly by the following criteria: (1) LWP between 20 and $600 \mathrm{gm}^{-2}$; (2) cloud-top height less than $3 \mathrm{~km}$; and (3) the range of radar reflectivity is between -60 to $0 \mathrm{dBZ}$ (Dong and Mace, 2003).

In the UND algorithm, cloud LWC is obtained in almost the same way as the UU algorithm, i.e., distributing the microwave radiometer-based LWP according to the $1 / 2$ th power of radar reflectivity. Similar to the MICROBASE and UU algorithms, the UND retrievals are also vulnerable to the presence of large particles. The main difference between the UND algorithm and the UU algorithm lies in their $r_{\mathrm{e}}$ retrievals.

Based on the availability of downward solar flux measurement at the surface, two methods are used to determine cloud droplet $r_{\mathrm{e}}$ : the M1 method and the M2 method. When solar flux measurements are available, the M1 approach is used. A mean cloud droplet radius $\overline{r_{\mathrm{e}}}$ is derived using the parameterization of Dong et al. (1998). In the Dong et al. (1998) parameterization, the mean $r_{\mathrm{e}}$ depends on LWP, solar transmission ratio $\gamma$, and cosine of solar zenith angle $\mu_{0}$ :

$$
\begin{aligned}
\overline{r_{\mathrm{e}}}= & -2.07+2.49 \mathrm{LWP}+10.25 \gamma \\
& -0.25 \mu_{0}+20.28 \mathrm{LWP} \gamma-3.14 \mathrm{LWP} \mu_{0}
\end{aligned}
$$

where the units of $r_{\mathrm{e}}$ and LWP are $\mu \mathrm{m}$ and $100 \mathrm{gm}^{-2}$, respectively. The cloud droplet $r_{\mathrm{e}}$ is then calculated as the product of the mean $r_{\mathrm{e}}$, the cloud thickness and the ratio of the radar reflectivity to the integrated radar reflectivity (Dong et al., 1998):

$$
r_{\mathrm{e} i}=\overline{r_{\mathrm{e}}} H \frac{Z_{i}^{0.5}}{\sum_{j=1}^{M} Z_{j}^{0.5} \Delta z},
$$

where $H$ is the cloud thickness. The summation is from cloud base $(j=1)$ to the highest liquid cloud layer $(j=M)$.

When the downward solar flux measurements are not available, e.g., during nighttime, a simple parameterization similar to that used in the UU algorithm (the M2 approach) is employed to calculate cloud droplet $r_{\mathrm{e}}$ (Dong and Mace, 2003):

$r_{\mathrm{e}}=22.0 \exp [0.384 \log 10(Z)]$.

The empirical coefficients in this simple parameterization were determined by statistically fitting observed daytime radar reflectivity $Z$ at the ARM SGP site during the 2001 IOP to the retrieved cloud droplet $r_{\mathrm{e}}$ using the M1 approach (Dong and Mace, 2003). 


\section{Intercomparison results}

The intercomparison studies are based on data at the SGP site from year 1998 to 2006, during which all three cloud products are available. The MICROBASE product is averaged to the same time and space grids as the UU product. Note that the averaging is performed for only the cloudy portion of the MICROBASE data and thus cloud fraction cannot be defined for time scales shorter than five minutes. Two sets of comparisons are performed in this study. The first set of comparison is intended to provide a quantitative estimate of the differences between the MICROBASE and UU cloud LWC and $r_{\mathrm{e}}$ retrievals for all types of clouds. To avoid complication of phase-partitioning and precipitation, the second set of comparisons focuses on only nonraining non-mixed-phase low-level stratus clouds from the MICROBASE, UU, and UND products. The definition of non-raining non-mixed-phase low-level stratus clouds are based on Dong and Mace (2003) (see Sect. 3.3) and two additional criteria: (1) total supercooled cloud LWC in the column is zero; and (2) the radar reflectivity factors throughout the column should not exceed $-20 \mathrm{dBZ}$ (Kato et al., 2001; Kogan et al., 2005). It should be noted that the simple reflectivity-based criteria for precipitation identification can be improved if additional information is available, e.g., large precipitation particles could be identified more accurately using full Doppler spectrum if the cloud and precipitation modes can be decomposed from the spectrum (Kollias et al., 2011a, b).

The columns where both the radar reflectivity and microwave LWP are available are selected for the comparisons by using one of the MICROBASE QC flags. The data points corresponding to the conditions where the microwave radiometer precipitation flag indicates "wet window" (i.e., precipitation at the ground level) are excluded from the intercomparisons because the microwave radiometer cannot provide a reliable retrieval of LWP when the radiometer window is wet (Liljegren et al., 2001).

\subsection{MICROBASE and UU retrievals for all clouds}

\subsubsection{Cloud occurrence}

In model evaluation studies, especially evaluation of modeled clouds against observations, statistical variation of cloud occurrence as a function of time and height is often an important feature to examine. In this study, cloud occurrence is defined as pixels (data points with 5-min temporal and 90-m vertical resolution) whose cloud LWC or IWC is positive. A vertical column is considered to be cloudy if at least one layer in the column is cloudy and is considered to be clear if every layer in the column is cloudless. Figure 1 shows the monthlymean MICROBASE cloud occurrence at the ARM SGP site from 1998 to 2006, which is calculated as the fraction of cloudy columns to the total number of 5-min columns in

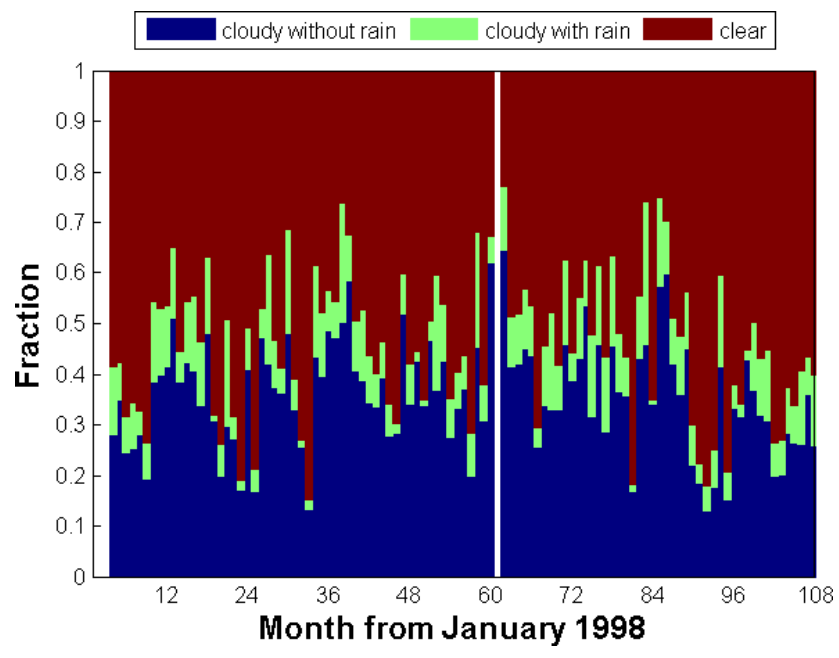

Fig. 1. Monthly mean cloud occurrence at the Atmospheric Radiation Measurement (ARM) Southern Great Plains (SGP) site from 1998 to 2006 based on the MICROBASE product. The length of each bar represents the fraction of occurrence. The University of Utah (UU) product (not shown here) shows almost identical seasonal variation. A profile is clear if the total cloud water content (liquid and ice) is zero, and otherwise it is cloudy. A profile is considered to be raining if there is at least one layer below the freezing level with radar reflectivity $Z>-20 \mathrm{dBZ}$.

each month. The plot for UU cloud occurrence is not shown here because it is almost identical to that of MICROBASE. The similarity between the MICROBASE and UU cloud occurrence is likely due to the fact that both products rely on the MMCR observations to determine cloud mask. Figure 1 shows that the monthly-mean cloud coverage ranges from 0.12 to 0.75 and there is considerable month-to-month variation at the SGP site.

Each cloudy column is further classified into raining or non-raining using the aforementioned radar reflectivitybased criteria. It can be seen from Fig. 1 that about 20-30\% of the cloudy columns are raining and this fraction has large month-to-month variation. As pointed out in Sect. 3, cloud liquid retrievals in mixed-phase regions are likely to suffer from large uncertainties. Table 1 further stratifies the cloudy columns with regards to the existence of mixed-phase clouds. It can be seen that about $70 \%$ of the cloudy columns do not contain mixed phase clouds. The percentage of non-raining, non-mixed phase, cloudy columns is $60 \%$ and without complications by rain and ice particles these columns are ideal cases for retrieval algorithm testing.

To avoid possible artifacts by very small cloud LWC retrievals, we define liquid cloud fraction as the fraction of 5-min data points with $\mathrm{LWC}>0.01 \mathrm{gm}^{-3}$ in each one-hour period. The reason for using a one-hour window to calculate liquid cloud fraction is that this time scale roughly corresponds to the typical resolution of climate model output (Xie et al., 2010). Figure 2 shows the contour of frequency 
Table 1. Cloud occurrence at the SGP site based on the 5-min resolution MICROBASE and UU retrievals from 1998 to 2006. A vertical column is considered to be cloudy when it contains at least one cloudy layer. A cloudy column is non-raining/non-mixed-phase when it contains no raining/mixed-phase layer.

\begin{tabular}{lrrrrr}
\hline & & & & $\begin{array}{r}\text { Non- } \\
\text { Non- } \\
\text { mixed- } \\
\text { phase }\end{array}$ & $\begin{array}{r}\text { Non-raining } \\
\text { and non- } \\
\text { mixed- } \\
\text { phase }\end{array}$ \\
\hline MICROBASE & 3.85 & 3.31 & 2.59 & 2.32 & 1.95 \\
UU & 3.82 & 3.31 & 2.60 & 2.29 & 1.93 \\
\hline
\end{tabular}
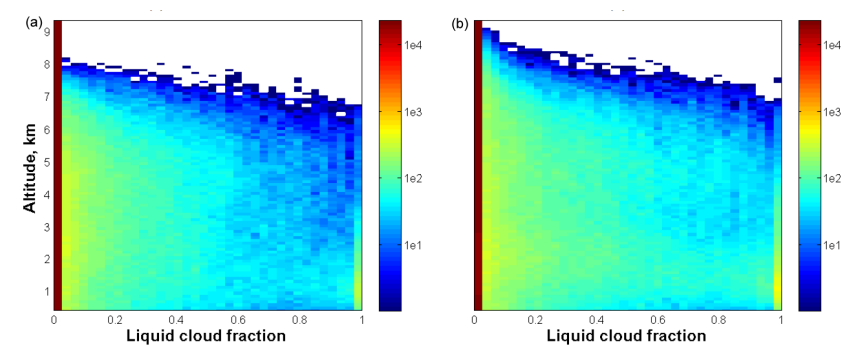

Fig. 2. Contour frequency by altitude diagrams (CFADs) of liquid cloud fraction from the 5-min MICROBASE and UU data for the period of 1998 to 2006. To avoid the artifact of very small cloud liquid water content (LWC) retrievals at high altitudes, the liquid cloud mask is defined as data points with $\mathrm{LWC}>0.01 \mathrm{gm}^{-3}$.

by altitude diagram (CFAD) for liquid cloud fraction for the MICROBASE and UU products. CFADs have been widely used in model evaluation studies to examine the ability of models to reproduce the observed statistical characteristics of clouds (Yuter and Houze, 1995). Both the MICROBASE and UU liquid cloud fraction shows a "U" shape distribution with high probability for very small or very large liquid cloud fraction values and low probability for intermediate cloud fraction values. The U-shaped distributions are similar to previous studies (Hogan et al., 2001).

\subsubsection{Monthly mean cloud properties}

Figure $3 \mathrm{a}$ and $\mathrm{b}$ show the monthly mean LWC from the MICROBASE and UU products as a function of altitude and time. The overall pattern of the monthly averages of LWC is very similar and the vertical extent of cloud LWC shows a similar seasonal cycle in the two cloud products. The top of the liquid layer is about $2.0 \mathrm{~km}$ higher in winter than that in summer and this can be explained by the seasonal variation of atmospheric temperature. In both products, the maximum cloud LWC occurs at low altitudes close to the surface and the decrease of cloud LWC with altitude is also evident. The small cloud LWC values $\left(<0.01 \mathrm{gm}^{-3}\right)$ in the UU product above $7.0 \mathrm{~km}$ is a retrieval artifact which is not likely to have a significant impact on radiation and other physical processes (Mace et al., 2006).
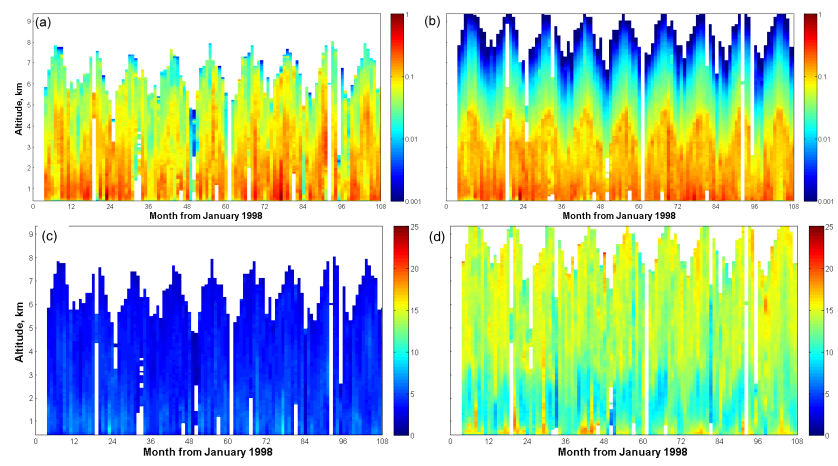

Fig. 3. Vertical profiles of monthly mean cloud LWC and droplet effective radius $\left(r_{\mathrm{e}}\right)$ from the MICROBASE and UU products at the SGP site for the period of 1998 to 2006.

There are several striking differences in the monthly variation of $r_{\mathrm{e}}$ between the two products (Fig. 3c and d). First, the cloud droplet $r_{\mathrm{e}}$ from the UU product is always several microns larger than that from the MICROBASE product. Second, the vertical variation of $r_{\mathrm{e}}$ from the two products are quite different. The MICROBASE $r_{\mathrm{e}}$ generally decreases with increasing altitude (but the decreasing trend is not evident for some months), whereas the UU $r_{\mathrm{e}}$ first decreases with altitude below $2.5 \mathrm{~km}$ and then increases rapidly with altitude above $3.0 \mathrm{~km}$ because the $r_{\mathrm{e}}$ retrievals of the liquid component of mixed phased clouds are contaminated by large ice particles. However, since the water content at high altitudes is negligible, the artifact should have no physical consequence.

\subsubsection{CFADs of cloud microphysical properties}

Probability density functions (PDFs) of cloud microphysical properties are not only useful for climate model evaluations but also important for process studies. Figure $4 \mathrm{a}$ and $\mathrm{b}$ further show the CFADs of 5-min MICROBASE and UU LWC retrievals, respectively. The probability distributions of cloud LWC from the two products appears to be similar. The distributions are wider at lower altitudes and the mean LWC values in general decrease with increasing altitude. Similar to the monthly mean comparisons shown in Sect. 4.2.3, the CFAD of UU LWC extends to higher altitudes than that of MICROBASE, a manifestation of the difference in their phase-partitioning algorithms.

The CFADs of MICROBASE and UU $r_{\mathrm{e}}$ retrievals are shown in Fig. 4c and d, respectively. Several differences can be identified. Firstly, the width of the probability distributions decreases with altitude in the MICROBASE retrievals while it is almost constant in the UU retrievals. Secondly, the MICROBASE $r_{\mathrm{e}}$ decreases with altitude and the UU $r_{\mathrm{e}}$ in general increases with altitude. Thirdly, the UU $r_{\mathrm{e}}$ is mostly larger than $3.0 \mu \mathrm{m}$, while there are a significant amount of MICROBASE retrievals smaller than $3.0 \mu \mathrm{m}$. Lastly, there is a spike around $15 \mu \mathrm{m}$ in the UU retrievals, which is likely 

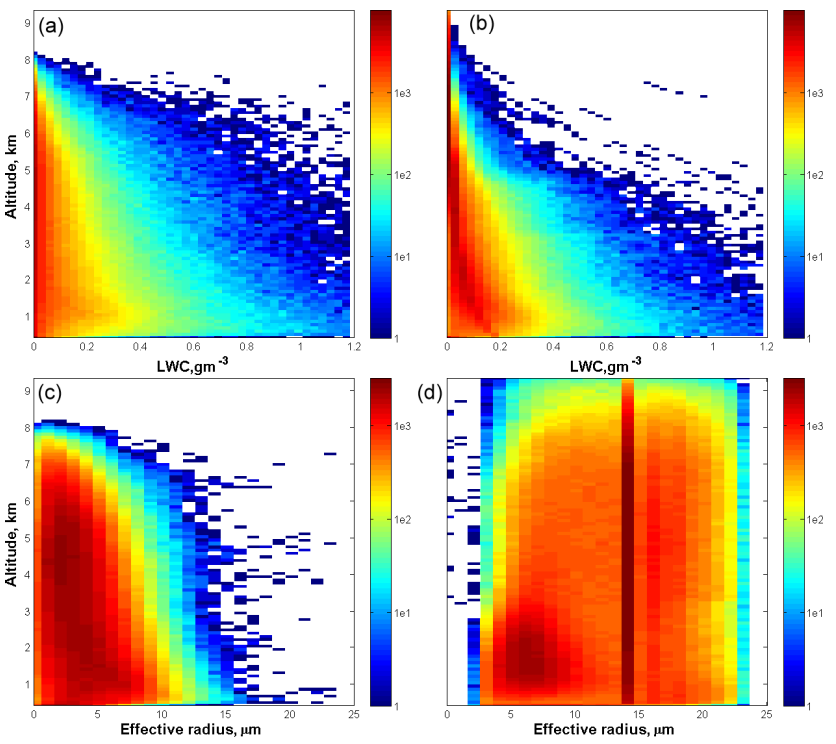

Fig. 4. CFADs of MICROBASE and UU LWC and $r_{\mathrm{e}}$ at the SGP site from 1998 to 2006.

due to the threshold value used by the UU algorithm for supercooled liquid droplets.

\subsubsection{Mean cloud properties as a function of normalized height}

In some cases, e.g., in the comparsion of cloud retrievals under different environmental conditions, it is also useful to examine cloud properties as a function of normalized height from cloud base (Löhnert et al., 2007). The MICROBASE and UU LWC vertical profiles are similar in shape but the locations of maximum LWC are slightly different (Fig. 5a). The difference between the two LWC profiles is small in the middle of cloud and increases to about $0.03 \mathrm{gm}^{-3}$ at both cloud base and cloud top. The standard deviation of MICROBASE LWC is slightly larger than that of UU and the differences between the two LWC retrievals are almost one order smaller than their standard deviations. The mean MICROBASE and UU LWC values are both about $0.12 \mathrm{gm}^{-3}$. The shape of the MICROBASE and UU $r_{\mathrm{e}}$ profiles is almost the same, while their magnitudes differ by more than a factor of two: the mean MICROBASE and UU $r_{\mathrm{e}}$ are 4.5 and $10.5 \mu \mathrm{m}$, respectively (Fig. 5b). The standard deviation of MICROBASE $r_{\mathrm{e}}$ is about a half of that of UU.

\subsection{MICROBASE, $\mathrm{UU}$, and UND retrievals for low-level non-raining non-mixed-phase stratus}

\subsubsection{Occurrence of non-raining non-mixed-phase stratus}

Figure 6 shows the CFAD for low-level, non-raining, nonmixed-phase, stratus cloud fraction (note that the cloud frac-
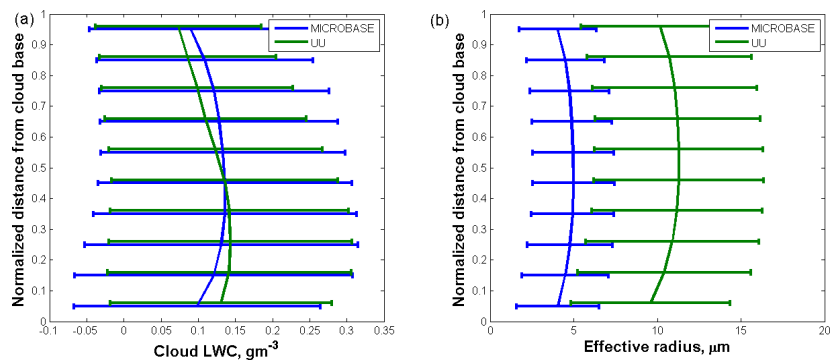

Fig. 5. Nine-year average MICROBASE and UU cloud LWC and $r_{\mathrm{e}}$ as a function of normalized distance from cloud base. Horizontal error bars represent the corresponding standard deviations. The UU profiles are shifted upward by 0.01 normalized distance for a better illustration.

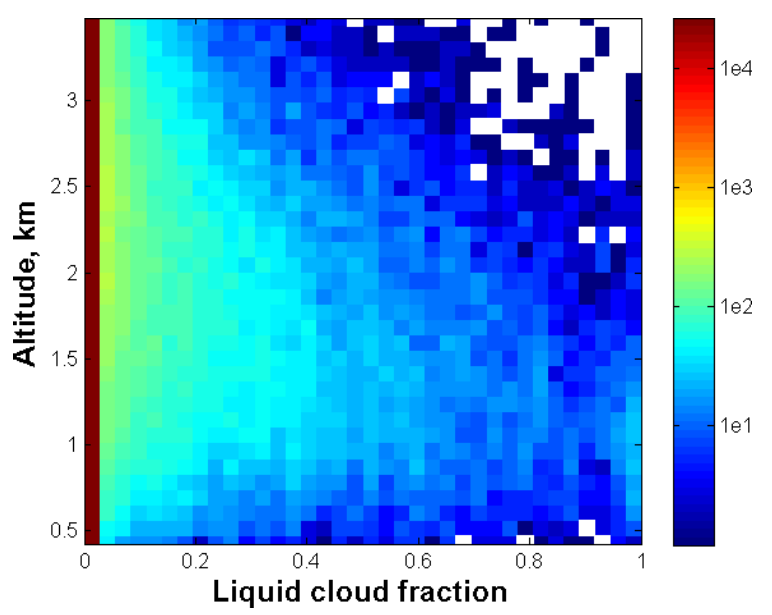

Fig. 6. CFAD of cloud fraction for non-raining non-mixed-phase low-level stratus from the University of North Dakota (UND) product at the SGP site from 1998 to 2006.

tions from the other two products are almost the same because the UND product is used to define the cloud mask). It is interesting to note that the " $U$ " shape variation of cloud fraction PDF in Fig. 2a and b is not seen here. Instead, the PDF decreases monotonically with liquid cloud fraction. The maximum liquid cloud fraction occurs around $1.5 \mathrm{~km}$. The probability that liquid cloud fraction being larger than 0.5 is very low.

\subsubsection{Monthly-mean cloud properties of non-raining non-mixed-phase stratus}

Figure 7a-c shows the monthly-mean vertical profiles of MICROBASE, UU, and UND LWC retrievals for non-raining non-mixed-phase stratus clouds. The monthly-mean profiles appear to be quite similar to each other during most of the months. Large differences are also found for a few months, e.g., the MICROBASE LWC has a spike of high values between 2.5 to $3.0 \mathrm{~km}$ around June 2005 (month 90 in the figure), while the UND LWC does not have a spike in this 


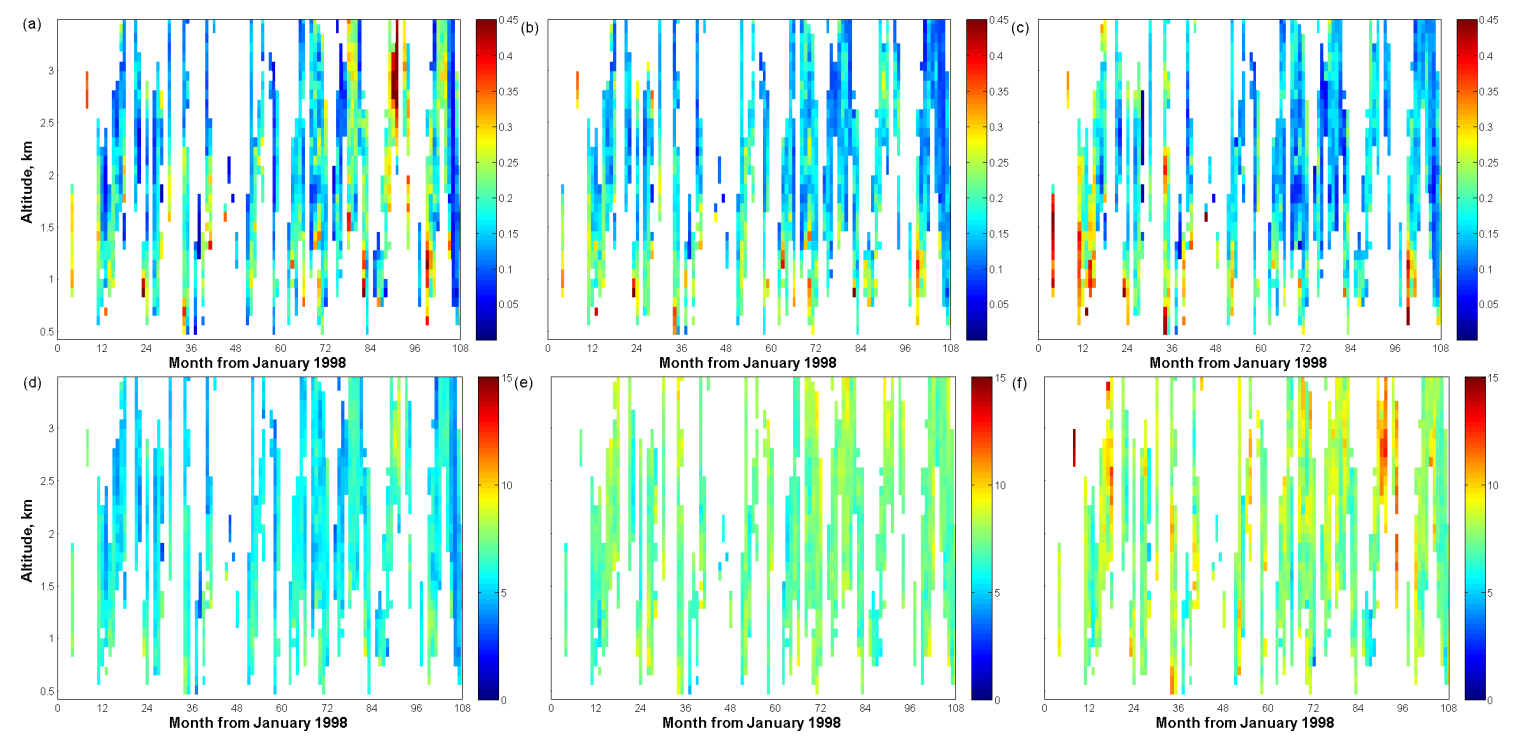

Fig. 7. Vertical profiles of monthly mean cloud LWC and $r_{\mathrm{e}}$ for low-level non-raining non-mixed-phase stratus from the MICROBASE, UU, and UND products for the period of 1998 to 2006.

month. To pinpoint the cause of this large difference requires an in-depth examination of the retrieval algorithms as well as their input data. The UND monthly-mean profiles have more liquid water below $1.5 \mathrm{~km}$ during the period of 1998 to 2000 (month 1 to month 36) than the other two retrievals.

There are considerable differences in both the magnitude and vertical distribution of cloud droplet $r_{\mathrm{e}}$ among the three retrievals (Fig. $7 \mathrm{~d}-\mathrm{f}$ ). The UND $r_{\mathrm{e}}$ retrievals, on average, are $1 \mu \mathrm{m}$ larger than the UU retrievals, and $1-2 \mu \mathrm{m}$ larger than the MICROBASE retrievals. The MICROBASE $r_{\mathrm{e}}$ decreases with altitude for most of the months while the decreasing trend with altitude is less evident in the UU and UND retrievals. The UND retrievals have some large values $\left(r_{\mathrm{e}}>10 \mu \mathrm{m}\right)$ around $2.5 \mathrm{~km}$.

\subsubsection{CFADs of cloud properties of non-raining non-mixed-phase stratus}

The overall shapes of the CFADs of MICROBASE, UU, and UND LWC for low-level non-raining non-mixed-phase stratus clouds are very similar, as shown in Fig. 8a-f. The similarity can be explained by the fact that all three retrievals use the microwave radiometer LWP as a constraint for each column and use the MMCR reflectivity to distribute the liquid water into each cloud layer. The PDFs of MICROBASE and UU LWC are almost identical at altitudes from the surface to $3.5 \mathrm{~km}$ and the PDFs decrease with increasing LWC. For the UU LWC retrievals, the PDF first increases then decreases with LWC below $1.5 \mathrm{~km}$.

The CFADs of MICROBASE, UU, and UND $r_{\mathrm{e}}$ are also similar, except that the MICROBASE CFAD is shifted by 1$2 \mu \mathrm{m}$ toward the origin. The MICROBASE $r_{\mathrm{e}}$ is rarely larger than $10 \mu \mathrm{m}$ while there are a significant number of points in the UND and UU retrievals that exceed $10 \mu \mathrm{m}$. The minimum $r_{\mathrm{e}}$ from the UU product is about $2.0 \mu \mathrm{m}$. On the other hand, the MICROBASE and UND effective radii are below $1 \mu \mathrm{m}$ in some cases. Overall, the UU $r_{\mathrm{e}}$ retrievals fall between the MICROBASE and UND retrievals.

\subsubsection{Mean cloud properties of non-raining non-mixed- phase stratus as a function of normalized height}

The mean profile of MICROBASE LWC for low-level, nonraining, non-mixed-phase, stratus clouds is similar to that of UU. The MICROBASE LWC increases from cloud base to middle of the cloud layer, and after reaching a maximum value it starts to decrease toward cloud top (Fig. 9a). The UND cloud LWC, on the other hand, remains almost constant from cloud base to the middle of cloud and then decreases monotonically toward cloud top. The discrepancy between the three LWC profiles is within $0.02 \mathrm{gm}^{-3}$, which is about $10 \%$ of their mean LWC values. The UU LWC profile falls between the MICROBASE and UND profiles.

The mean MICROBASE, UU, and UND droplet effective radii remain constant from cloud base to the middle of the cloud layer and decrease slowly when moving toward cloud top (Fig. 9b). The MICROBASE $r_{\mathrm{e}}$ ranges from 5.0 to $6.0 \mu \mathrm{m}$, while the UU and UND effective radii are respectively 1.0 and $2.0 \mu \mathrm{m}$ larger (Fig. 9b). Overall, the discrepancy between the three $r_{\mathrm{e}}$ retrievals for non-raining nonmixed-phase clouds are much smaller than that for all clouds, indicating that precipitation and phase-partitioning are possibly responsible for the large differences in the $r_{\mathrm{e}}$ retrievals for all clouds. 


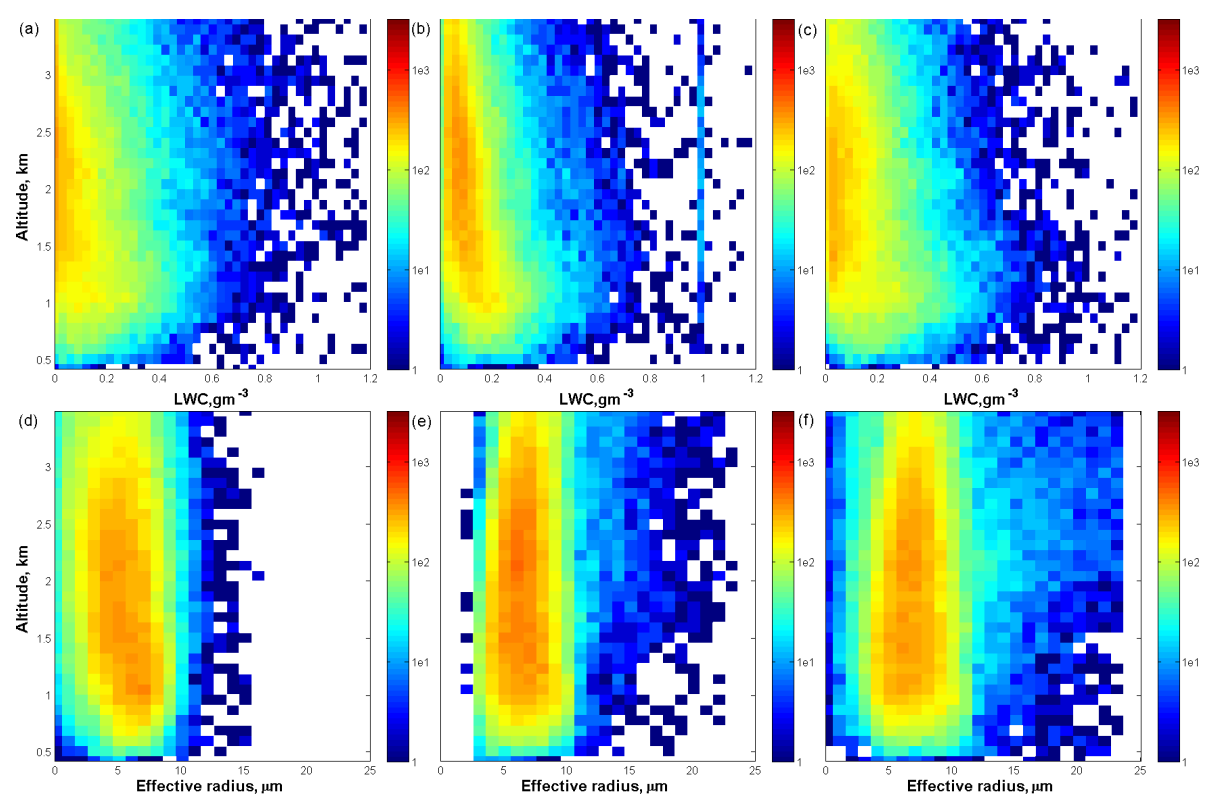

Fig. 8. CFADs of MICROBASE, UU, and UND LWC and $r_{\mathrm{e}}$ e for low-level non-raining non-mixed-phase stratus from 1998 to 2006.
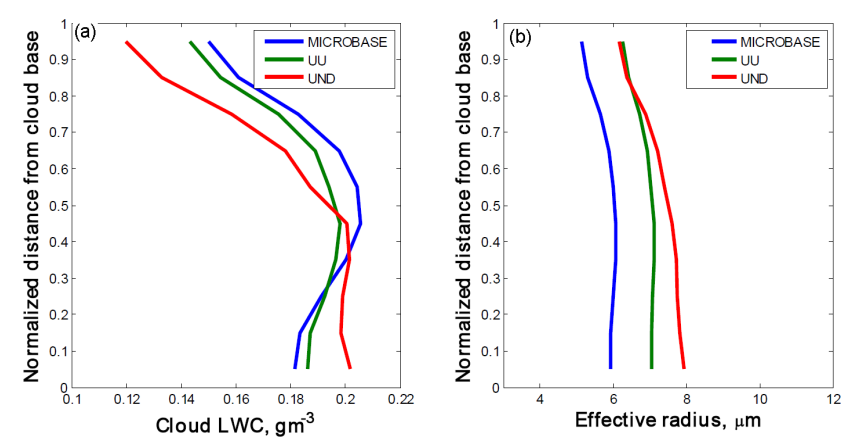

Fig. 9. MICROBASE, UU, and UND cloud LWC (a) and $r_{\mathrm{e}}(\mathbf{b})$ as a function of normalized height for low-level non-raining liquid stratus from 1998 to 2006.

\section{Further analysis and discussion}

Section 4 reveals the large differences between the retrieved cloud microphysical properties, e.g., the mean MICROBASE $r_{\mathrm{e}}$ is about $6.0 \mu \mathrm{m}$ smaller than that of UU. When only nonraining non-mixed-phase stratus clouds are considered, the MICROBASE and UU/UND effective radii show a much better agreement with the discrepancy being reduced to 1$2 \mu \mathrm{m}$. This section provides a stratified analysis with the intent to pinpoint possible reasons for the large differences found in Sect. 4. As described in Sect. 3, the UND algorithm is very similar to the UU algorithm except: (1) it focuses on only low-level stratus clouds; and (2) it uses more information than the other two algorithms (i.e., solar transmission). Therefore, the UND product is not included in the analysis of cloud LWC and only serves as a reference in the analysis of cloud droplet $r_{\mathrm{e}}$ since it satisfies one more observational constraint.

\subsection{Factors for the difference in cloud LWC retrievals}

According to Sect. 3, the uncertainty in LWC retrievals will certainly propagate to the calculation of $r_{\mathrm{e}}$ in the MICROBASE algorithm. It is therefore necessary to examine the difference in cloud LWC retrievals before we can pinpoint the causes for the large difference in $r_{\mathrm{e}}$ retrievals.

Based on the description of the MICROBASE and UU retrieval algorithms (Sect. 3), the retrieved LWC profiles depend on the following factors:

1. input data - radar reflectivity, total column liquid water (LWP), and radar reflectivity boundaries for the MICROBASE algorithm/cloud boundaries for the UU algorithm (both are referred to as cloud boundaries thereafter);

2. partitioning of total liquid water into warm and supercooled liquid water;

3. treatment of rain/drizzle contamination;

4. expressions used to distribute warm liquid water in warm cloud layers, i.e., the difference between the exponents used in Eqs. (7) and (10).

The MICROBASE and UU algorithms use different approaches to merge the different MMCR modes into a single description of radar reflectivity factor in each layer. As mentioned in Sect. 3, there are also some differences between the LWPs used by MICROBASE and UU algorithms. They make their own specific bias correction or quality check. The 


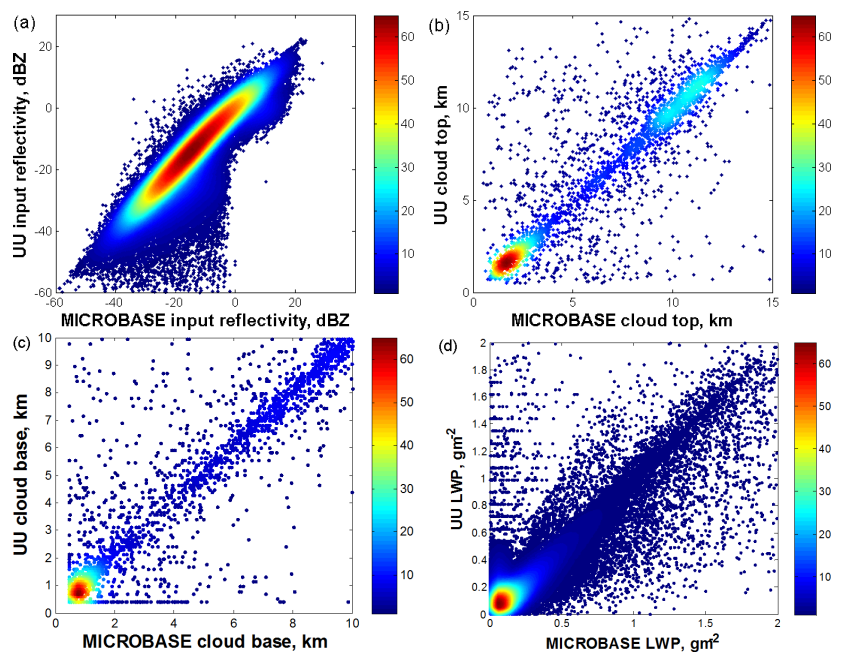

Fig. 10. Scatter plots of MICROBASE and UU input radar reflectivity factors (a), cloud base heights (b), cloud top heights (c), and cloud LWPs (d) from 1998 to 2006 . Color coding is used to indicate point density.

UU product computes the bias as a function of precipitable water path and MICROBASE product performs some quality checks by indicating those questionable periods. These different bias corrections and quality checks could result in non-negligible differences in the LWP constraints. To evaluate the impact of inputs to cloud LWC retrievals, we first examine the differences in the MICROBASE and UU input data. The input data used by the MICROBASE algorithm are averaged to 5-min temporal resolution and the average is performed for only cloudy columns. Figure 10 shows the scatter plots of various input data used in the MICROBASE and UU algorithms from 1998 to 2006. It can be seen that the MICROBASE and UU radar reflectivity factors generally agree with each other. There are also a considerable number of cases where the UU radar reflectivity is larger than that of MICROBASE (Fig. 10a). Both the cloud lower and upper boundaries agree with each other reasonably well, although large differences are also occasionally found (Fig. 10b, c). The MICROBASE and UU LWPs agree well when LWP is high while the agreement is not as good for the more frequently-found low LWPs (Fig. 10d).

The impacts of the second and third factors are examined through several stratified comparisons. Figure 11a shows that in the lower part of cloud, the MICROBASE LWC is consistently smaller than the UU LWC and the largest difference of $0.03 \mathrm{gm}^{-3}$ occurs around cloud base. On the other hand, in the upper part of cloud, the MICROBASE LWC is higher than the UU LWC with the largest difference of $0.03 \mathrm{gm}^{-3}$ around cloud top. When raining columns are excluded from the comparison, the shape of the LWC vertical profiles changes remarkably and the magnitude of the two LWC retrievals is reduce by $20-40 \%$ in the lower part of cloud (Fig. 11b). Figure 11c shows the comparison re-
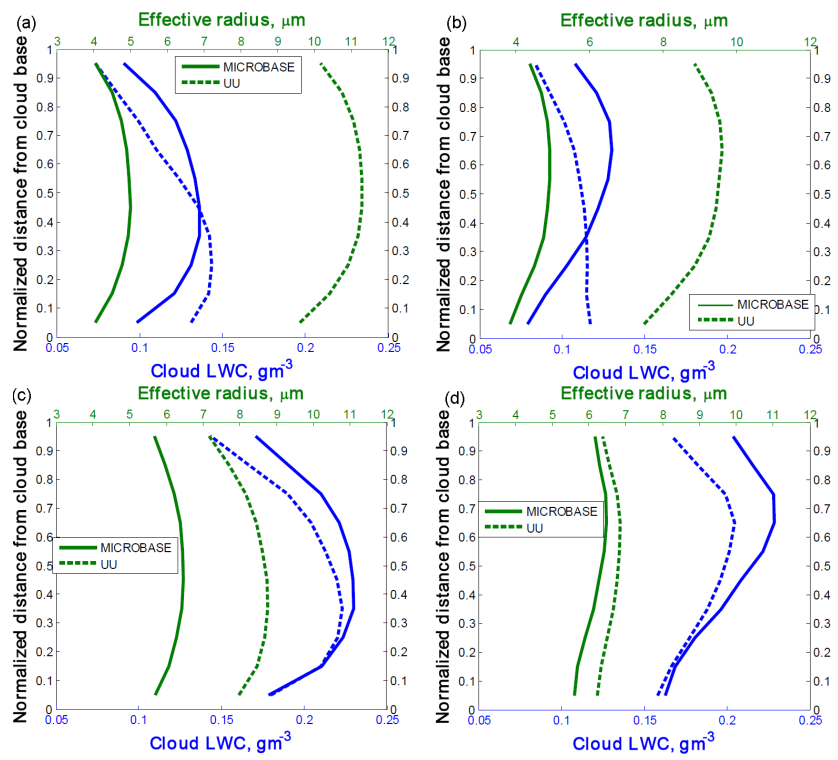

Fig. 11. MICROBASE and UU cloud LWC and $r_{\mathrm{e}}$ as a function of normalized height from cloud base for the period of 1998 to 2006. Solid and dashed lines indicate respectively MICROBASE and UU retrievals, while green and blue colors represents $r_{\mathrm{e}}$ and LWC. (a) all clouds; (b) columns without raining layers; (c) columns without mixed-phase layers; and (d) columns without raining or mixedphase layers.

sults for only non-mixed-phase clouds (no supercooled liquid in each column). It can be seen that from cloud base to 0.3 normalized height, the comparison is improved significantly while the difference around cloud top remains about the same. When both raining and mixed-phase columns are excluded (Fig. 11d), the LWC profiles are similar to that in Fig. 11c, i.e., a negligible difference at cloud base and the difference increase with normalized height. These stratified comparisons show that phase partitioning and rain contamination are largely responsible for the large difference between the MICROBASE and UU LWC retrievals in the lower part of cloud but they cannot explain the large difference found in the upper part of cloud.

To examine the impact of the fourth factor on cloud LWC retrievals, a straightforward approach is to perform retrieval experiments for cloudy columns containing no rain and no supercooled liquid. For these non-raining columns, the only difference between the MICROBASE and UU algorithm is the expressions to distribute liquid water in each vertical profile. The MICROBASE algorithm is modified to use the UU input data. The resultant cloud LWC retrievals (blue dashed line) are compared with the standard UU retrievals (solid green line) to evaluate the impact of the fourth factor (Fig. 12a). It can be seen from Fig. 12a that the fourth factor contributes less than $5 \%$ of the differences between the MICROBASE and UU LWC retrievals. Therefore, it can be concluded that the large difference between the MICROBASE 

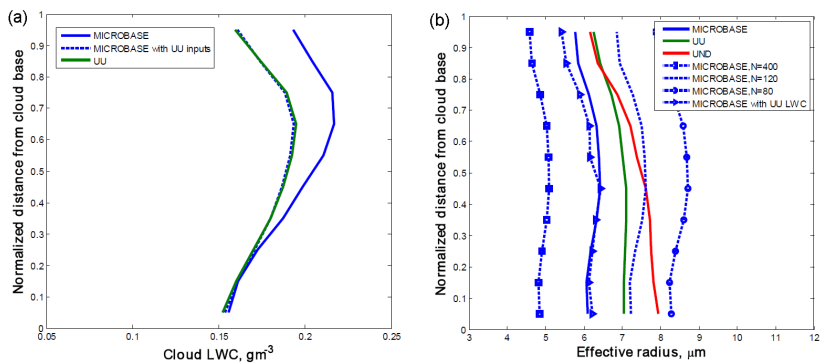

Fig. 12. Cloud LWC and $r_{\mathrm{e}}$ retrievals as a function of normalized height from a suite of retrieval experiments. In (a), the MICROBASE LWC algorithm is modified to use the UU input data and the experiment is based on non-raining non-mixed-phase cases at the SGP site from 1998 to 2006. In (b), the MICROBASE $r_{\mathrm{e}}$ algorithm is modified to use UU LWC retrievals and different droplet number concentrations and only non-raining non-mixedphase low-level stratus cases are considered. Note that the standard MICROBASE algorithm uses $N=200 \mathrm{~cm}^{-1}$.

and UU LWC retrievals cannot be explained by the difference in the exponents used in Eqs. (7) and (10).

The only difference in the production of the dashed (MICROBASE with UU input data) and the solid blue line) and solid (standard MICROBASE) blue lines is their input data. Therefore the negligible difference between the two lines indicates that the difference in input data is mainly responsible for the large difference between MICROBASE and UU LWC retrievals in the upper part of cloud shown in Figs. 11 and 12.

\subsection{Factors for the differences in $r_{\mathrm{e}}$ retrievals}

After identifying the factors responsible for the difference in the MICROBASE and UU LWC retrievals, the factors for the striking difference in $r_{\mathrm{e}}$ can be examined. Green lines in Fig. 11a-d show the mean MICROBASE and UU $r_{\mathrm{e}}$ as a function of normalized height from cloud base for different cloud conditions. When all clouds are included in the comparison, the discrepancy is about $7.0 \mu \mathrm{m}$ (Fig. 11a). Excluding raining profiles reduces the discrepancy to $5.0 \mu \mathrm{m}$ (Fig. 11b), while excluding mixed-phase columns further reduces the discrepancy to about $2.5 \mu \mathrm{m}$ (Fig. 11c). When both raining and mixed-phase columns are taken out from the comparison, the mean MICROBASE and UU effective radii agree with each other within $1.0 \mu \mathrm{m}$ (Fig. 11d). Therefore, it is likely that rain contamination and mixed-phase clouds are mainly responsible for the large difference found in the MICROBASE and UU $r_{\mathrm{e}}$ retrievals.

From now on, we focus on only low-level non-raining non-mixed-phase stratus clouds because: (1) the complication of phase-partitioning and rain contamination can be avoided; and (2) the UND product can serve as a reference here since it uses more observation constraints. We first show the connection between the MICROBASE algorithm and the empirical UU algorithm.
According to Eq. (5b), if one assumes that the cloud droplet size distribution is a lognormal distribution with fixed total number concentration $N$ and geometric standard deviation of the droplet size distribution $\sigma$, cloud droplet $r_{\mathrm{e}}$ can be expressed as:

$r_{\mathrm{e}}=a \exp [0.384 \log 10(Z)]$.

Eq. (15) is very similar to the empirical relationship used in the UU $r_{\mathrm{e}}$ retrieval algorithm. The first coefficient $a=$ $0.5 N^{-1 / 6} \exp \left(0.5 \sigma^{2}\right)$ depends on both droplet number concentration and standard deviation of the droplet size distribution. It is easy to verify that the coefficient $a=0.0195$ used in the UU algorithm can be obtained by assuming $N=200 \mathrm{~cm}^{-1}$ and $\sigma=0.35$. The second coefficient 0.384 is a result of assuming radar reflectivity is proportional to the square of cloud LWC and a different exponent in the Z-LWC relationship will result in a different coefficient. Roughly speaking, the UU algorithm can be thought of as a variant of the algorithms that assume a lognormal size distribution with fixed number concentration and standard deviation of the droplet size distribution.

Note that the LWC profile from Eq. (5) is rescaled using LWP derived from a microwave radiometer. According to Eqs. (9) and (15), the effect of rescaling the LWC profile on $r_{\mathrm{e}}$ is equivalent to rescaling coefficient $a$ in Eq. (15). On the other hand, the empirical relationship used by the UU algorithm to calculate $r_{\mathrm{e}}$ is solely based on observed radar reflectivity factor and has no dependency on the microwave radiometer LWP.

Below are three parameters that can be modified in the MICROBASE algorithm to examine the behavior of $r_{\mathrm{e}}$ retrievals: (1) cloud LWC; (2) choice of droplet number concentration; and (3) choice of standard deviation of the droplet size distribution. Based on the discussions above, we will examine the impacts of the first two factors on $r_{\mathrm{e}}$ retrieval since both algorithms explicitly or implicitly use the same standard deviation of the droplet size distribution.

To evaluate the magnitude of uncertainty propagated from cloud LWC retrievals into the $r_{\mathrm{e}}$ retrievals, the standard MICROBASE algorithm is first modified to take the LWC profiles from the UU product as the input. The resultant $r_{\mathrm{e}}$ retrievals are then compared with those from the standard MICROBASE and UU products. Figure $12 \mathrm{~b}$ shows that from cloud base to the middle of cloud, the difference in input LWC profiles contributes negligibly to the difference between the MICROBASE and UU $r_{\mathrm{e}}$ retrievals. From the middle of cloud to cloud top, it causes a difference of about $0.2 \mu \mathrm{m}$.

The impact of the choice of droplet number concentration on $r_{\mathrm{e}}$ is evaluated as follows. The MICROBASE algorithm is modified to use $N=80,120$, and $400 \mathrm{~cm}^{-1}$, respectively. The comparison between the resultant mean $r_{\mathrm{e}}$ retrievals averaged over the period of 1998 to 2006 is shown in Fig. 12b. It can be seen that the assumption of droplet 
number concentration can dramatically change the magnitude of the MICROBASE $r_{\mathrm{e}}$. The MICROBASE $r_{\mathrm{e}}$ profile matches the reference UU profile reasonably well when a droplet number concentration of $120 \mathrm{~cm}^{-1}$ is used. On the other hand, it is also evident that the shape of the $r_{\mathrm{e}}$ profiles is hardly changed when the number concentration changes from 80 to $400 \mathrm{~cm}^{-1}$. To summarize, the lack of constraint for droplet number concentration is partially responsible for the difference between the $r_{\mathrm{e}}$ retrievals for non-raining nonmixed-phase cloud columns.

\section{Implications for model evaluation}

Cloud microphysical retrievals can be used in different types of applications, e.g., evaluating cloud resolving models and climate models where cloud microphysical processes are parameterized. Model intercomparison or model/observation comparison studies typically focus on quantities such as cloudiness, cloud LWC and LWP when evaluating cloud simulations. Different applications may have different requirements for retrieval accuracy of cloud properties and model evaluation studies should carefully account for the uncertainties in observations or retrievals. Zhang et al. (2005) shows that the majority of ten selected GCMs only simulate $30-40 \%$ of middle-top clouds in the satellite datasets and half of these models underestimate low clouds. Xie et al. (2005) evaluates the overall performance of nine SCMs and four CRMs in simulating a frontal cloud system using ARM observations. It was found that these SCMs and CRMs typically capture the bulk characteristics of the frontal system but significant differences exist in the detailed structures of the frontal clouds. Klein et al. (2009) shows that cloud LWPs for an arctic mixed phase cloud from 17 single column GCMs vary from 5.8 to $291.8 \mathrm{~g} \mathrm{~m}^{-2}$ with a median value of $56.0 \mathrm{~g} \mathrm{~m}^{-2}$, while the LWPs for the same cloud from 9 CRMs range from $1.6 \mathrm{~g} \mathrm{~m}^{2}$ to $172.6 \mathrm{~g} \mathrm{~m}^{-2}$ with a median value of $57.3 \mathrm{~g} \mathrm{~m}^{-2}$. The spreads between SCM and CRM cloud LWC vertical profiles are even larger, typically three to five times of the median LWC values. Su et al. (2011) found that modeled LWC in the boundary layer is only $60-70 \%$ of the LWC values retrieved from CloudSat observations, and the discrepancy between vertical profiles of total cloud water content from three GCMs is more than a factor of 5 at some altitudes. It can be seen from these studies that the spread in modeled cloud water content is much larger than that in radar-based retrievals; this implies that, despite the large spread in cloud LWC retrievals of existing cloud products, these retrievals are still useful datasets for evaluating cloud models and cloud representations in GCMs.

Cloud droplet $r_{\mathrm{e}}$ is a critical parameter in determining cloud optical properties but it is not predicted by most GCMs (Slingo, 1990). It is instead parameterized based on cloud LWC and/or some large-scale conditions. Slingo (1990) showed that the top-of-the-atmosphere radiative forcing by doubled carbon dioxide can be balanced by increases of 20$35 \%$ in total liquid water, or by decreases of approximately $15-20 \%$ in mean cloud droplet radius. In other words, in order to effectively constrain cloud radiative impacts and therefore climate sensitivity, an accuracy better than $15 \%$ for cloud retrievals will be required. The relatively large discrepancy in cloud LWC and $r_{\mathrm{e}}$ retrievals indicates that cloud microphysical retrievals are yet to be improved to effectively constrain climate sensitivity.

For applications such as evaluation of high-resolution cloud models or other process models, cloud microphysics retrievals from remotely sensed data are not yet sufficiently accurate to resolve small-scale (temporal and spatial) cloud radiative heating structure (Mace and Benson, 2008). Improvements of both observational techniques and retrieval algorithms are clearly needed for continued progress.

\section{Concluding remarks}

To examine if the existing ground-based cloud retrievals are able to provide a useful constraint for model evaluation and radiation budget studies, this paper statistically compares three cloud products that use ARM data as inputs over the nine-year period from 1998 to 2006. It is found that the mean MICROBASE and UU cloud LWC retrievals agree well in the middle of cloud and the discrepancy increases to about $0.03 \mathrm{gm}^{-3}$ at cloud top and cloud base. The CFADs of the MICROBASE and UU LWC appear to be consistent with each other. The mean MICROBASE $r_{\mathrm{e}}$ is about $6 \mu \mathrm{m}$ lower than the UU $r_{\mathrm{e}}$. When columns containing rain and mixed-phase clouds are excluded, the comparisons improved dramatically. The CFADs of MICROBASE, UU, and UND LWC and $r_{\mathrm{e}}$ are very similar and the discrepancy between the three $r_{\mathrm{e}}$ retrievals is reduced to $1-2 \mu \mathrm{m}$. In general, the spread in the non-precipitating warm cloud retrievals is smaller than the spread between GCMs, but it is still larger than the requirement set by Slingo (1990) for radiation budget studies.

We then attempt to pinpoint the primary causes of the large differences between different radar-based cloud retrievals and to understand the limitation of the single-frequency radar approaches. Two approaches are used: (1) stratified comparisons that gradually exclude raining and mixed-phase columns; and (2) retrieval experiments with modified retrieval algorithms. It is found that the difference in input data (LWP, radar reflectivity, and cloud mask) explains most of the LWC difference in the upper part of clouds, while rain contamination and phase partitioning are responsible for the LWC difference in the lower part. The large difference in $r_{\mathrm{e}}$ retrievals can also be explained by rain contamination and phase partitioning. It is shown that the MICROBASE $r_{\mathrm{e}}$ is very sensitive to the assumption of cloud droplet concentration. Unfortunately, single-frequency radar reflectivity alone cannot provide useful constraints simultaneously for droplet number concentration and $r_{\mathrm{e}}$. These 
findings are consistent with the underlying assumptions of the radar-based retrieval algorithms. When rain or ice particles co-exist with cloud droplets in the same volume, the assumptions about the relationships between cloud droplets and radar reflectivity will be largely violated. Therefore, the radar-based cloud retrievals are most reliable when there are no raining and mixed-phase layers present in the column; for other conditions they should be used with caution.

The large spread among different cloud retrievals not only suggests caution in application of these products to evaluate model performance but also calls for new techniques to go beyond the physically limited single-frequency radar. Several recent advances offer some new insights on possible improvements on cloud microphysics retrievals. Studies have already demonstrated that radar attenuation can be obtained from dual-frequency radar observations and can be used to derive unbiased vertical profiles of cloud LWC (Hogan et al., 2005; Huang et al., 2009). The dual-frequency radar approach takes advantage of the fact that microwave attenuation is directly proportional to the mass of liquid water in the Rayleigh scattering regime and thus requires no assumptions about the cloud droplet size distribution. The dual-frequency approach is therefore immune to drizzle and light rain contamination. It is also possible to extract cloud information reliably using full Doppler spectra or multiple Doppler moments instead of only reflectivity, as proposed by Luke et al. (2010) and Kollias et al. (2011a, b). The spectrum-based approach is able to separate (at least partially) the cloud droplet contribution from the more dominant drizzle/ice contribution and therefore cloud droplet properties can be more accurately retrieved.

Acknowledgements. This work is supported by the Climate System Modeling (ESM) via the FASTER project (www.bnl.gov/esm) and most of the co-authors are supported by Atmospheric Science Research (ASR) programs of the US Department of Energy.

Edited by: A. Macke

\section{References}

Ackerman, T. and Stokes, G.: The atmospheric radiation measurement program, Phys. Today, 56, 38-45, 2003.

Clothiaux, E. E., Miller, M. A., Albrecth, B. A., Ackerman, T. P., Verlinde, J., Babb, D. M., Peters, R. M., and Syrett, W. J.: An evaluation of a $94 \mathrm{GHz}$ radar for remote sensing of cloud properties, J. Atmos. Ocean. Technol., 12, 201-229, 1995.

Clothiaux, E. E., Ackerman, T., Mace, G., Moran, K., Marchand, R., Miller, M., and Martner, B.: Objective Determination of Cloud Heights and Radar Reflectivities Using a Combination of Active Remote Sensors at the ARM CART Sites, J. Appl. Meteorol., 39, 645-665, 2000.

Cober, S. G., Isaac, G. A., and Strapp, J. W.: Aircraft icing measurements in east coast winter storms, J. Appl. Meteorol., 34, 88-100, 1995.
Comstock, J.M., D’Entremont, R., De Slover, D., Mace, G. G., Matrosov, S. Y., McFarlane, S. A., Minnis, P., Mitchell, D., Sassen, K., Shupe, M. D., Turner, D. D., and Wang, Z.: An Intercomparison of Microphysical Retrieval Algorithms for UpperTropospheric Ice Clouds, B. Am. Meteorol. Soc., 88, 191-204, 2007.

Dong, X. and Mace, G. G.: Profiles of low-level stratus cloud microphysics deduced from ground-based measurements, J. Atmos. Ocean. Technol., 20, 45-53, 2003.

Dong, X., Ackerman, T. P., Clothiaux, E. E., Pilewskie, P., and Han, Y.: Microphysical and Radiative Properties of Stratiform Clouds Deduced from Ground-based Measurements, J. Geophys. Res., 102, 23829-23843, 1997.

Dong, X., Ackerman, T. P., and Clothiaux, E. E.: Parameterizations of Microphysical and Radiative Properties of Boundary Layer Stratus from Ground-based measurements, J. Geophys. Res., 102, 31681-31393, 1998.

Doviak, R. J. and Zrnic, D. S.: Doppler Radar and Weather Observations, 2nd Edn., Elsevier, New York, 1993.

Dunn, M., Johnson, K. L., and Jensen, M. P.: The Microbase calue-added product: A baseline retrieval of cloud microphysical properties, DOE/SC-ARM/TR-095, available at: http://www. arm.gov/publications/tech_reports/doe-sc-arm-tr-095.pdf, 2011.

Ebell, K., Lohnert, U., Crewell, S., and Turner, D. D.: On characterizing the error in a remotely sensed liquid water content profile, Atmos. Res., 96, 57-68, 2010.

Frisch, A. S., Fairall C. W., and Snider, J. B.: Measurement of stratus cloud and drizzle parameters in ASTEX with a Ka-band Doppler radar and a microwave radiometer, J. Atmos. Sci., 52, 2788-2799, 1995.

Frisch, A. S., Feingold, G., Fairall, C. W., Uttal, T., and Snider, J. B.: On cloud radar and microwave radiometer measurements of status liquid water profiles, J. Geophys. Res., 113, 23195-23197, 1998.

Hobbs, P., Funk, N., Weiss Sr., R., Locatelli, J., and Biswas, K.: Evaluation of a $35 \mathrm{GHz}$ radar for cloud physics research, J. Atmos. Ocean. Technol., 2, 35-48, 1985.

Hogan, R. J., Jakob, C., and Illingworth, A. J.: Comparison of ECMWF cloud fraction with radar-derived values, J. Appl. Meteorol., 40, 513-525, 2001.

Hogan, R. J., Gaussiat, N., and Illingworth, A.: Stratocumulus liquid water content from dual-wavelength radar, J. Atmos. Ocean. Technol., 22, 1207-1218, 2005.

Huang, D., Johnson, K., Liu, Y., and Wiscombe, W.: Retrieval of cloud liquid water vertical distributions using collocated Kaband and W-band cloud radars, Geophys. Res. Lett., 36, L24807, doi:10.1029/2009GL041364, 2009.

Kato, S., Mace, G., Clothiaux, E. E., Liljegren, J., and Austin, R.: Doppler cloud radar derived drop size distributions in liquid water stratus clouds, J. Atmos. Sci., 58, 2895-2911, 2001.

Kiehl, J. T., Bonan, G. B., Boville, B. A., Briegleb, B. P., Williamson, D. L., and Rasch, P. J.: The National Center for Atmospheric Research Community Climate Model: CCM3. J. Climate, 11, 1131-1150, 1998.

Klein, S. A., McCoy, R. B., Morrison, H., Ackerman, A. S., Avramov, A., de Boer, G., Chen, M. N., Cole, J. N. S., Del Genio, A. D., Falk, M., Foster, M. J., Fridlind, A., Golaz, J. C., Hashino, T., Harrington, J. Y., Hoose, C. M., Khairoutdinov, F., Larson, V. E., Liu, X., Luo, Y., McFarquhar, G. M., Menon, S., 
Neggers, R. A. J., Park, S., Poellot, M. R., Schmidt, J. M., Sednev, I., Shipway, B. J., Shupe, M. D., Spangenberg, D. A., Sud, Y. C., Turner, D. D., Veron, D. E., von Salzen, K., Walker, G. K., Wang, Z., Wolf, A. B., Xie, S., Xu, K., Yang, F., and Zhang, G.: Intercomparison of model simulations of mixed-phase clouds observed during the ARM Mixed-Phase Arctic Cloud Experiment. I: single-layer cloud, Q. J. Roy. Meteorol. Soc., 135, Part B, 979-1002, 2009.

Kogan, Z. N., Mechem, D. B., and Kogan, Y. L.: Assessment of variability in continental low stratiform clouds based on observations of radar reflectivity, J. Geophys. Res., 110, D18205, doi.10.1029/2005JD006158, 2005.

Kollias, P., Albrecht, B., Clothiaux, E., Miller, M., Johnson, K., and Moran, K.: The Atmospheric Radiation Measurement Program Cloud Profiling Radars: An Evaluation of Signal Processing and Sampling Strategies, J. Atmos. Ocean. Technol., 22, 930-948, 2005.

Kollias, P., Remillard, J., Luke, E., and Szyrmer, W.: Cloud radar Doppler spectra in drizzling stratiform clouds: 1 . Forward modeling and remote sensing applications, J. Geophys. Res., 116, D13201, doi:10.1029/2010JD015237, 2011a.

Kollias, P., Szyrmer, W., Remillard, J., and Luke, E.: Cloud radar Doppler spectra in drizzling stratiform clouds: 2. Observations and microphysical modeling of drizzle evolution, J. Geophys. Res., 116, D13203, doi:10.1029/2010JD015238, 2011 b.

Lhermitte, R.: A $94 \mathrm{GHz}$ Doppler radar for clouds observations, J. Atmos. Ocean. Technol., 4, 36-48, 1987.

Liao, L. and Sassen, K.: Investigation of relationships between Kaband radar reflectivity and ice and liquid water contents, J. Atmos. Sci., 35, 231-248, 1994.

Liljegren, J. C., Clothiaux, E. E., Mace, G. G., Kato, S., and Dong, X.: A new retrieval for cloud liquid water path using a groundbased microwave radiometer and measurements of cloud temperature, J. Geophys. Res., 106 14485-14500, 2001.

Liu, Y., Geerts, B., Miller, M., Daum, P., and McGraw, R.: Threshold radar reflectivity for drizzling clouds, Geophys. Res. Lett., 35, L03807, doi:10.1029/2007GL031201, 2008.

Löhnert, U., Crewell, S., Macke, A., and Simmer, C.: Profiling cloud liquid water by combining active and passive microwave measurements with cloud model statistics, J. Atmos. Ocean. Technol., 18, 354-1366, 2001.

Löhnert, U., van Meijgaard, E., Baltink, H. K., Groß, S., and Boers, R.: Accuracy assessment of an integrated profiling technique for operationally deriving profiles of temperature, humidity, and cloud liquid water, J. Geophys. Res., 112, D04205, doi:10.1029/2006JD007379, 2007.

Luke, E. P., Kollias, P., and Shupe, M. D.: Detection of supercooled liquid in mixed-phase clouds using radar doppler spectra, J. Geophys. Res., 115, D19201, doi:10.1029/2009JD012884, 2010.

Mace, G. G. and Benson, S.: The vertical distribution of cloud radiative forcing at the SGP ARM Climate Research Facility as revealed by 8 -years of continuous data, J. Climate, 21, 2591-2610, 2008.

Mace, G. G. and Sassen, K.: A constrained algorithm for retrieval of stratocumulus cloud properties using solar radiation, microwave radiometer, and millimeter cloud radar data, J. Geophys. Res., 105, 29099-29108, 2000.

Mace, G. G., Benson, S., Sonntag, K. L., Kato, S., Min, Q., Minnis, P., Twohy, C. H., Poellot, M., Dong, X., Long, C., Zhang,
Q., and Doelling, D. R.: Cloud radiative forcing at the Atmospheric Radiation Measurement Program Climate Research Facility: 1. Technique, validation, and comparison to satellitederived diagnostic quantities, J. Geophys. Res., 111, D11S90, doi:10.1029/2005JD005921, 2006.

McFarlane S. A. and Evans, K. F.: louds and Shortwave Fluxes at Nauru. Part II: Shortwave Flux Closure, J. Atmos. Sci., 6121, 2602-2615, 2004.

Matrosov, S.: Attenuation-based estimates of rainfall rates aloft with vertically pointing Ka-band radars, J. Atmos. Ocean. Technol., 22, 43-54, 2005.

Mlawer, E., Shippert, T., Johnson, K. L., Troyan, D., Miller, M. A., Delamere, J., Turner, D. D., Jensen,M. P. , Flynn, C., Shupe, M., Comstock, J., Long, C. N., Clough, S. T., Sivaraman, C., Dunn, M., Khaiyer, M., Xie, S., Rutan, D., and Minnis, P.: Evaluating cloud retrieval algorithms with the ARM BBHRP framework. Eighteenth Annual Atmospheric Radiation Measurement ARM Science Team Meeting, Norfolk, VA, 10-14 March, 2008.

Moran, K. P., Martner, B. E., Post, M. J., Kropfli, R. A., Welsh, D. C., and Widener, K. B.: An unattended cloud-profiling radar for use in climate research, B. Am. Meteorol. Soc., 79, 443-455, 1998.

Randall, D. A., Curry, J., Duynkerke, P. G., Krueger, S., Ryan, B., Starr, D., Miller, M., Rossow, W. B., and Wielicki, B. A.: Confronting models with data: The GEWEX Cloud Systems Study, B. Am. Meteorol. Soc, 84, 455-469, 2003.

Sassen, K., Mace, G. G., Wang, Z., Poellot, M. P., Sekelsky, S. M., and McIntosh, R. E.: Continental stratus clouds: A case study using coordinated remote sensing and aircraft measurements, J. Atmos. Sci., 56, 2345-2358, 1999.

Slingo, A.: Sensitivity of the Earth's radiation budget to changes in low clouds, Nature, 343, 49-51, 1990.

Stephens, G. L.: Cloud feedbacks in the climate system: a critical review, J. Climate, 18, 237-273, 2005.

Stokes, G. M. and Schwartz, S. E.: The Atmospheric Radiation Measurement ARM Program: Programmatic background and design of the Cloud and Radiation Testbed, B. Am. Meteorol. Soc., 75, 1201-1221, 1994.

Su, H., Jiang, J. H., Teixeira, J., Gettelman, A., Huang, X., Stephens, G., Vane, D., and Perun, V. S.: Comparison of regime-sorted tropical cloud profiles observed by CloudSat with GEOS5 analyses and two general circulation model simulations, J. Geophys. Res., 116, D09104, doi:10.1029/2010JD014971, 2011.

Troyan, D.: Merged Sounding Value-Added Product, Technical Report, DOE/SC-ARM/TR-087, 2010.

Turner, D. D., Clough, S. A., Liljegren, J. C., Clouthiaux, E. E., Cady-Pereira, K., and Gaustad, K. L.: Retrieving liquid water path and precipitable water vapor from the Atmospheric Radiation Measurement ARM microwave radiometers, IEEE T. Geosci. Remote Se., 45, 3680-3689, 2007.

Xie, S., Zhang, M., Branson, M., Cederwall, R. T., Del Genio, A. D., Eitzen, Z. A., Ghan, S. J., Iacobellis, S. F., Johnson, K. L., Khairoutdinov, M., Klein, S. A., Krueger, S. K., Lin, W., Lohmann, U., Miller, M. A., Randall, D. A., Somerville, R., Sud, Y. C., Walker, G. K., Wolf, A., Wu, X., Xu, K.-M., Yio, J. J., Zhang, G., and Zhang, J. H.: Simulations of midlatitude frontal clouds by single-column and cloud-resolving models during the Atmospheric Radiation Measurement March 2000 cloud intensive operational period, J. Geophys. Res., 110, D15S03, 
doi:10.1029/2004JD005119, 2005.

Xie, S., McCoy, R. B., Klein, S. A., Cederwall, R. T., Wiscombe, W. J., Clothiaux, E. E., Gaustad, K. L., Golaz, J., Hall, S. D., Jensen, M. P., Johnson, K. L., Lin, Y., Long, C. N., Mather, J. H., McCord, R. A., McFarlane, S. A., Palanisamy, G., Shi, Y., and Turner, D. D.: Clouds and More: ARM Modeling Best Estimate Data, B. Am. Meteorol. Soc., 91, 13-20, 2010.

Yuter, S. E. and Houze Jr., R. A.: Three-Dimensional Kinematic and Microphysical Evolution of Florida Cumulonimbus. Part II: Frequency Distributions of Vertical Velocity, Reflectivity, and Differential Reflectivity, Mon. Weather Rev., 123, 1941-1963, 1995.
Zhang, M. H., Lin, W. Y., Klein, S. A., Bacmeister, J. T., Bony, S., Cederwall, R. T., Del Genio, A. D., Hack, J. J., Loeb, N. G., Lohmann, U., Minnis, P., Musat, I., Pincus, R., Stier, P., Suarez, M. J., Webb, M. J., Wu, J. B., Xie, S. C., Yao, M.-S., and Zhang, J. H.: Comparing clouds and their seasonal variations in 10 atmospheric general circulation models with satellite measurements, J. Geophys. Res., 110, D15S02, doi:10.1029/2004JD005021, 2005.

Zhao, C., Xie, S., Klein, S. A., Protat, A., Shupe, M. D., McFarlane, S. A., Comstock, J. M., Delanoe, J., Deng, M., Dunn, M., Hogan, R. J., Huang, D., Jensen, M. P., Mace, G. G., McCoy, R., O'Connor, E. J., Turner, D. D., and Wang, Z.: Towards understanding of differences in current cloud retrievals of ARM ground-based measurements, J. Geophys. Res., 117, D10206, doi:10.1029/2011JD016792, 2012. 